\title{
Forecasting sector-wise electricity consumption for India using various regression models
}

\author{
Renuka Rekhade $^{1, *}$ and D. K. Sakhare ${ }^{2}$ \\ ${ }^{1}$ Department of Mechanical Engineering, Ramdeobaba College of Engineering and Management, Katol Road, Nagpur 440 013, India \\ ${ }^{2}$ CSIR-Central Institute of Mining and Fuel Research, Nagpur Research Centre (Fuel Sciences), 17/C, Telangkhedi Area, Civil Lines, \\ Nagpur 440 001, India
}

Electricity is an important and one of the most dominant energy sources used in the world. It governs a major share in the Indian as well as world economy. Thus, forecasting its consumption can be useful in better planning of its future production and supply. In the present study, electricity consumption in seven different sectors, namely industry, domestic, agriculture, commercial, traction and railways, others along with total electricity consumed is forecasted using regression analysis. The study uses four regression modelling approaches to forecast electricity consumption by sectors in India. These are linear, logarithmic, power and exponential regression models. The accuracy of the models is tested using $R^{2}$ (coefficient of determination) and MAPE (mean absolute percentage error) values. The model having the highest $R^{2}$ and lowest MAPE value is selected for better accuracy results. The result/forecast is then compared with the available data published by the Central Electricity Authority, Government of India.

Keywords: Electricity consumption, energy policy, forecasting, regression analysis.

ELECTRICITY is one of the most important energy sources in India. It can be used for many applications and in different sectors such as industry, agriculture, domestic, commercial, traction and railways and others. Among these, the industrial sector is found to dominate the consumption of electricity.

\section{Literature review}

Electricity forecasting has been done employing various methods to predict electricity price and/or demand forecasting. Some of them are regression models, time-series models, artificial neural networks (ANNs), genetic programming, ARIMA models, etc.

Morales and Acevedo ${ }^{1}$ forecasted future electrical energy demand in Mexico for the next 40 years. The study first defined and then took into account three

*For correspondence. (e-mail: renukarekhade24@gmail.com) variables, viz. population growth rate, gross domestic product (GDP) per capita and energy intensity for prediction. The forecast was based on a simple model on the future evolution of variables for different scenarios. The researchers ${ }^{1}$ had also recommended some suggestions to electrical energy planners and policy makers based on their results obtained.

Bianco et $a l^{2}$ forecasted electricity consumption in Italy using multiple and single regression models. The models were developed using historical electricity consumption data $^{2}$, GDP per capita and population. The developed forecast was then compared with the available national forecast.

Çunkas and Taskiran ${ }^{3}$ used genetic programming to predict future electricity consumption in Turkey. They used electricity energy production and consumption data of Turkey for the analysis. The results obtained were then compared with regression analysis techniques and the available estimates given by the Ministry of Energy and Natural Resources in Turkey ${ }^{3}$.

Ghosh and $\mathrm{Das}^{4}$ focused on the monthly forecast of electricity demand for Maharashtra, India. The study used multiplicative seasonal autoregressive integrated moving average (MSARIMA) method for analysis. The results did not suggest any major changes for the forecasted period, thus following the same trend with the seasonal variation $^{4}$.

Guerrero and Berumen ${ }^{5}$ used information provided by the consumers along with historical electricity-consumption data to forecast short-term electricity consumption in Mexico. The study used univariate time-series models for analysis.

Panklib et $a l .{ }^{6}$ forecasted electricity consumption using ANN and multiple linear regression in Thailand. ANN gave more accurate results than the regression models. The basis of comparison of performance was coefficient of determination, mean absolute percentage error and root mean square error.

Rao and Ghosh ${ }^{7}$ forecasted the monthly peak demand of electricity in India. They evaluated the monthly peak demand forecasting performance given by the Central Electricity Authority (CEA), Government of India (GoI), using trend method and then compared it with their predictions made using MSARIMA. The results showed that 


\section{RESEARCH ARTICLES}

the MSARIMA model was more accurate than the CEA $\operatorname{model}^{7}$

Sigauke and $\mathrm{Chikobvu}^{8}$ predicted the peak electricity demand in South Africa using time-series model. The study used hourly electricity data of 10 years for the forecast.

\section{Data and methodology}

In this study, we collected historical sector-wise electricity consumption data from 'energy statistics' reports in 2020, 2018 and 2009 by the National Statistical Office, Ministry of statistics and programme implementation, Government of India. The data was collected for the years between 1970 and 2018 (Figure 1).

For sector-wise modelling of electricity consumption simple regression analysis was used to find the relation-

Table 1. Equations of four regression models

\begin{tabular}{llc}
\hline Regression type & \multicolumn{1}{c}{ Equation } & $R^{2}$ \\
\hline Linear regression model & $y=7663.7 x-48,788$ & 0.7382 \\
Logarithmic regression model & $y=93121 \ln (x)-133,936$ & 0.4369 \\
Power regression model & $y=10319 x^{0.775}$ & 0.7436 \\
Exponential regression model & $y=25564 \mathrm{e}^{0.0557 x}$ & 0.9575 \\
\hline
\end{tabular}

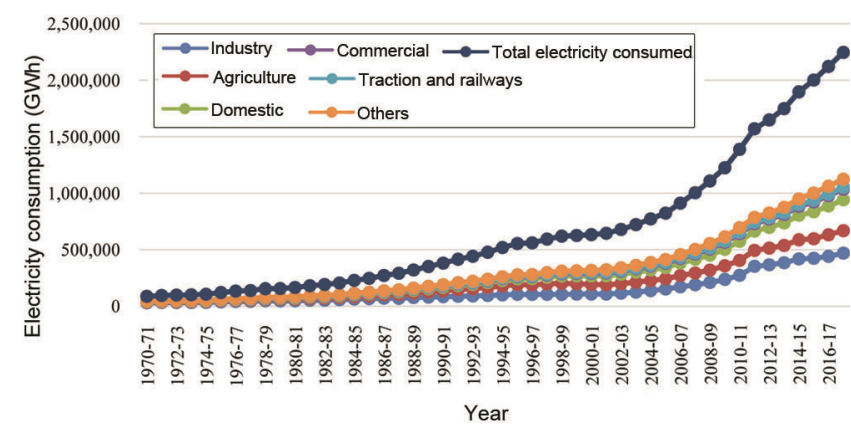

Figure 1. Actual electricity consumption $(\mathrm{GWh})$ by sectors (19702018).

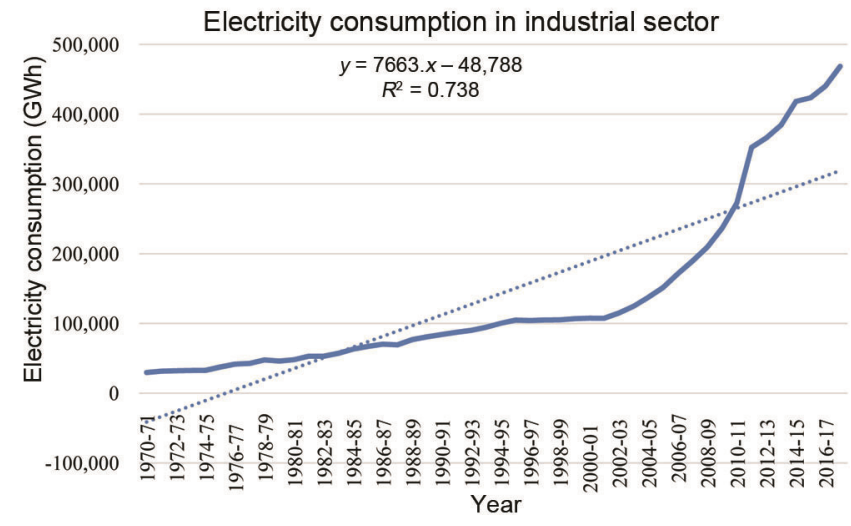

Figure 2. Linear regression model. ship between dependent and independent variables, and thereby the future values of dependent variables. We analysed the past and present data to establish the relationship between electricity consumption and period (1970-2018). The advantage lies in the simplicity of the analysis and the forecast is based on the available data.

Four types of regression models were used, viz. linear, logarithmic, power and exponential. Modelling was done for electricity consumption for each sector. Each regression model generated a modelling equation and their respective $R^{2}$ values were estimated. Microsoft Excel was used for modelling. The derived equations were then used for predicting the future values of electricity consumption by each sector. Also, their corresponding errors were estimated.

\section{Modelling electricity consumption}

For each sector, i.e. industry, agriculture, domestic, commercial, traction and railways, others and total electricity consumed, regression analysis was carried out. The regression models with the highest $R^{2}$ and lowest mean absolute percentage error (MAPE) values was selected.

For instance, regression analysis for the industrial sector is explained below. The analysis includes plotting of data, finding the best-fit line and calculating errors. Table 1 shows the equations of the four regression models along with their $R^{2}$ values. Table 2 shows the errors of the four regression models which give the best-suited model based on MAPE values. Figures 2-5 show the trendline of each model.

$R^{2}$ is the coefficient of determination used to find the most suitable model. A higher $R^{2}$ suggests better accuracy. MAPE is the average of the ratio of absolute error to actual value of historical data. The regression model having the lowest MAPE value was selected. Smaller values of MAPE suggest better prediction. Table 3 shows the results of regression analysis for each sector. The table indicates that all the sectors show better results

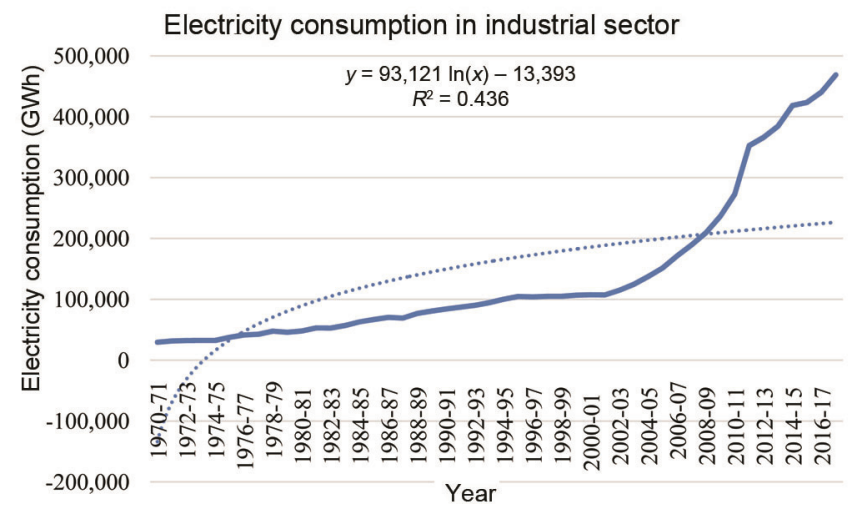

Figure 3. Logarithmic regression model. 
RESEARCH ARTICLES

Table 2. Errors generated in various regression models

\begin{tabular}{lrccc}
\hline Regression type & ME & MAE & $\begin{array}{c}\text { Mean absolute percentage } \\
\text { error (MAPE) }\end{array}$ & Mean square error \\
\hline Linear & -1504 & $51,817.45$ & 0.5086 & $3,977,114,600.36$ \\
Logarithmic & -3480 & $72,586.70$ & 0.6772 & $8,212,915,242.76$ \\
Power & 20,063 & $52,057.04$ & 0.3055 & $7,469,379,663.86$ \\
Exponential & 6421 & $24,003.41$ & 0.1267 & $1,586,613,084.59$ \\
\hline
\end{tabular}

Table 3. Results of regression analysis

\begin{tabular}{lcccc}
\hline Sectors & $\begin{array}{c}\text { Type of regression } \\
\text { model selected }\end{array}$ & $\begin{array}{c}\text { Equation of selected } \\
\text { model }\end{array}$ & MAPE & $R^{2}$ \\
\hline Industry & Exponential & $y=25564 \mathrm{e}^{0.0557 x}$ & 0.1267 & 0.9575 \\
Agriculture & Exponential & $y=6642.6 \mathrm{e}^{0.0773 x}$ & 0.2345 & 0.9312 \\
Domestic & Exponential & $y=3704.2 \mathrm{e}^{0.0935 x}$ & 0.1137 & 0.9903 \\
Commercial & Exponential & $y=2132.1 \mathrm{e}^{0.0796 x}$ & 0.0600 & 0.9950 \\
Traction and railways & Exponential & $y=1352.1 \mathrm{e}^{0.0555 x}$ & 0.0563 & 0.9920 \\
Others & Exponential & $y=1578.2 \mathrm{e}^{0.0779 x}$ & 0.0527 & 0.9959 \\
Total electricity consumed & Exponential & $y=40776 \mathrm{e}^{0.0686 x}$ & 0.0664 & 0.9932 \\
\hline
\end{tabular}

Table 4. Forecasted electricity consumption (GWh) by sectors

\begin{tabular}{|c|c|c|c|c|c|c|c|}
\hline $2018-19$ & 391,696 & $293,302.2$ & 361,755 & 105,373 & $20,515.1$ & $71,764.1$ & $1,175,553$ \\
\hline $2020-21$ & 437,854 & $342,339.7$ & 436,142 & 123,558 & $22,923.4$ & 83,863 & $1,348,427$ \\
\hline $2021-22$ & 462,934 & $369,852.2$ & 478,888 & 133,795 & $24,231.6$ & $90,657.2$ & $1,444,175$ \\
\hline $2024-25$ & 547,129 & $466,381.3$ & 633,948 & 169,883 & $28,621.5$ & 114,524 & $1,774,180$ \\
\hline $2025-26$ & 578,469 & $503,862.5$ & 696,082 & 183,958 & $30,254.9$ & 123,802 & $1,900,161$ \\
\hline $2026-27$ & 611,604 & 544,356 & 764,305 & 199,200 & $31,981.5$ & 133,832 & $2,035,087$ \\
\hline $2027-28$ & 646,637 & $588,103.8$ & 839,215 & 215,704 & $33,806.7$ & 144,674 & $2,179,594$ \\
\hline $2028-29$ & 683,677 & $635,367.4$ & 921,467 & 233,576 & 35,736 & 156,395 & $2,334,361$ \\
\hline $2033-34$ & 903,237 & $935,146.7$ & $1,470,661$ & 347,758 & $47,165.3$ & 230,877 & $3,289,509$ \\
\hline $2034-35$ & 954,975 & $1,010,301$ & $1,614,801$ & 376,571 & 49,857 & 249,581 & $3,523,090$ \\
\hline $2035-36$ & $1,009,676$ & $1,091,495$ & $1,773,069$ & 407,772 & $52,702.3$ & 269,801 & $3,773,256$ \\
\hline $2036-37$ & $1,067,511$ & $1,179,214$ & $1,946,849$ & 441,557 & 55,710 & 291,659 & $4,041,187$ \\
\hline $2037-38$ & $1,128,659$ & $1,273,983$ & $2,137,661$ & 478,142 & $58,889.3$ & 315,288 & $4,328,142$ \\
\hline $2038-39$ & $1,193,309$ & $1,376,368$ & $2,347,174$ & 517,758 & 62,250 & 340,830 & $4,635,474$ \\
\hline $2039-40$ & $1,261,662$ & $1,486,981$ & $2,577,222$ & 560,656 & $65,802.6$ & 368,443 & $4,964,628$ \\
\hline
\end{tabular}

for the exponential regression model. The MAPE value for all sectors lies between 0.05 and 0.23 . Whereas $R^{2}$ has a range 0.93-0.99, which shows good relationship between electricity consumption and year. Both MAPE and $R^{2}$ suggest better prediction accuracy.

\section{Forecasting sector-wise electricity consumption}

The results were analysed for each sector and the predicted values, i.e. future values of electricity consumption by each sector were estimated.
Table 4 shows the forecasted sector-wise electricity consumption in India from 2018 to 2040. All the sectors show increase in their trend.

\section{Industrial sector}

Figure 6 shows the increasing trend of the industrial sector from 2018-19 to 2039-40. In the year 2020-21, electricity consumption in the industrial sector would be $437,854 \mathrm{GWh}$ which will further increase to $722,838 \mathrm{GWh}$ in 2029-30. The increase till year 2039-40 will result into $1,261,662 \mathrm{GWh}$ electricity consumption. 


\section{Agricultural sector}

Figure 7 shows an increase in electricity consumption in the agricultural sector for the next 20 years. A total of $342,339.7 \mathrm{GWh}$ electricity will be consumed till 2020-21. In the coming 10 years, i.e. in 2030-31, electricity consumption in the agricultural sector will increase to $741,595.1 \mathrm{GWh}$, and to $1,486,981 \mathrm{GWh}$ in 2039-40.

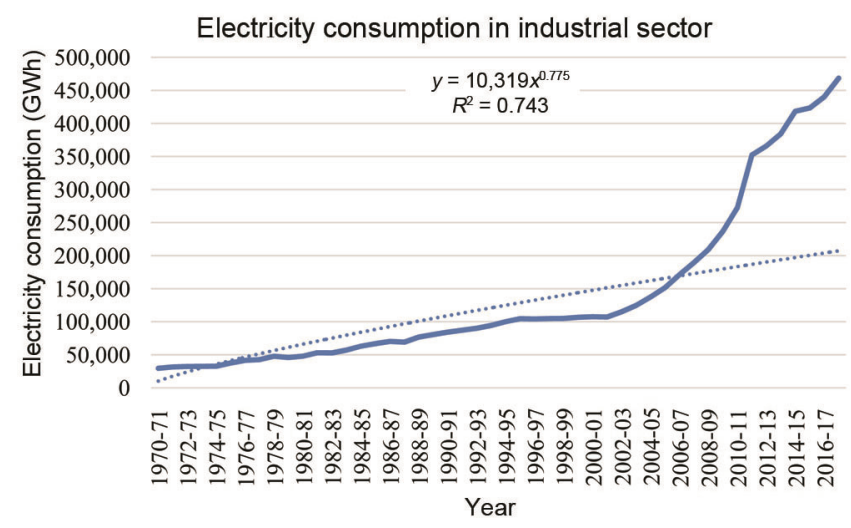

Figure 4. Power regression model.

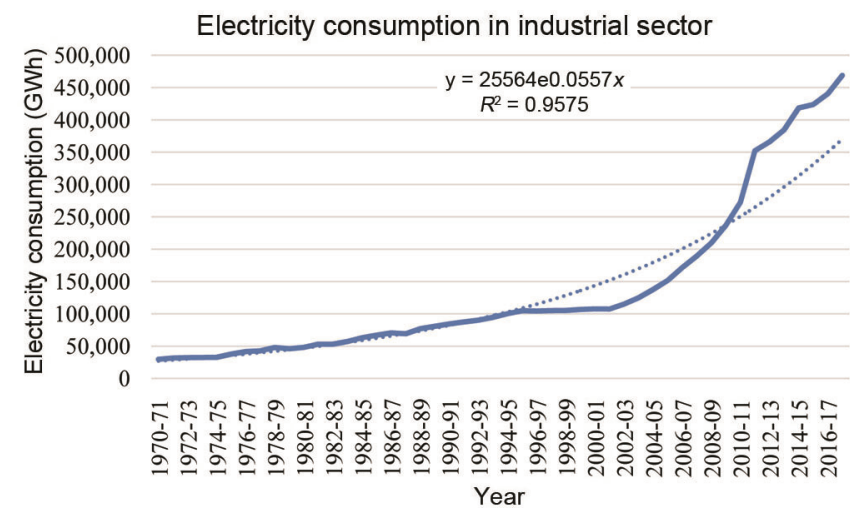

Figure 5. Exponential regression model.

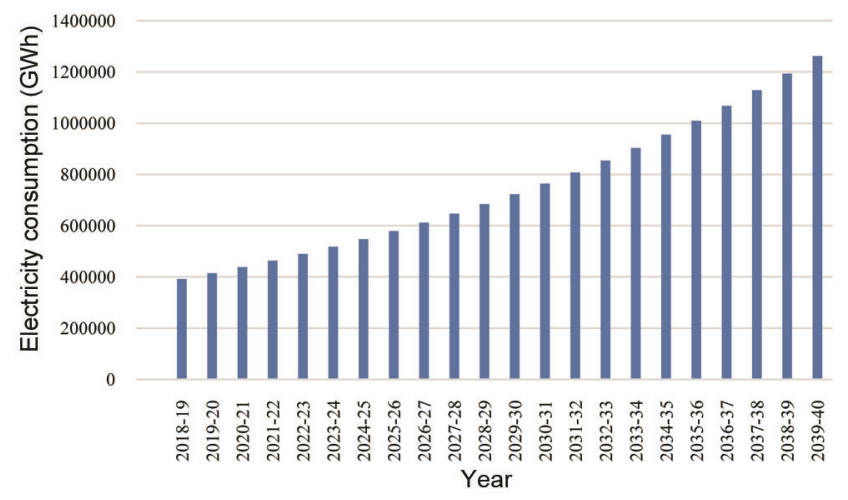

Figure 6. Forecasted electricity consumption $(\mathrm{GWh})$ for industrial sector (2018-2040).

\section{Domestic sector}

For the domestic sector (Figure 8), electricity shows an increasing trend in consumption in the next 20 years, from $397,211 \mathrm{GWh}$ in $2019-20$ to $2,577,222 \mathrm{GWh}$ in 2039-40.

\section{Commercial sector}

As shown in Figure 9, electricity consumption will increase from $123,558 \mathrm{GWh}$ in $2020-21$ to $273,885 \mathrm{GWh}$

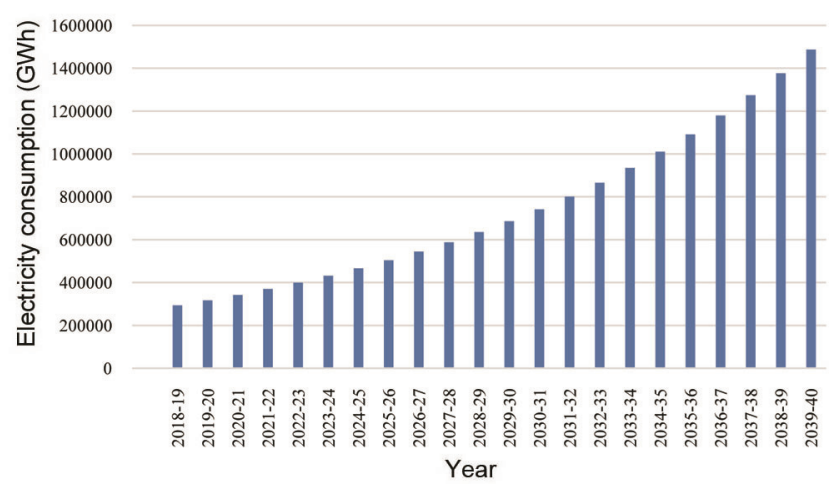

Figure 7. Forecasted electricity consumption $(\mathrm{GWh})$ for agricultural sector $(2018-2040)$.

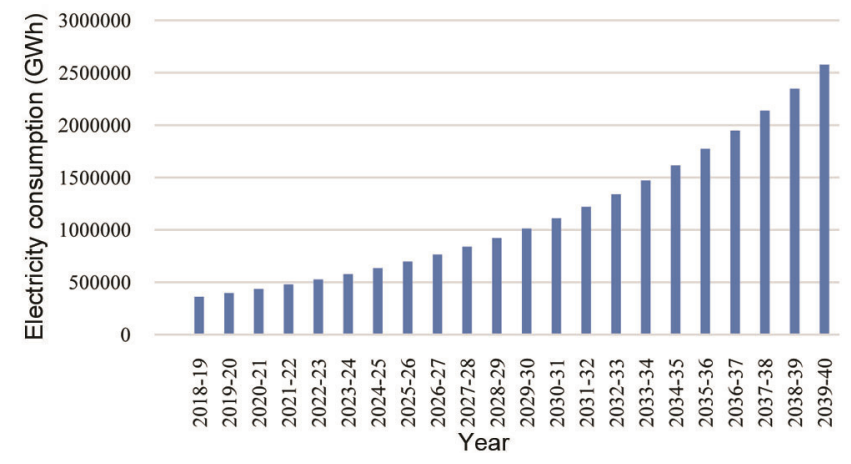

Figure 8. Forecasted electricity consumption (GWh) for domestic sector (2018-40).

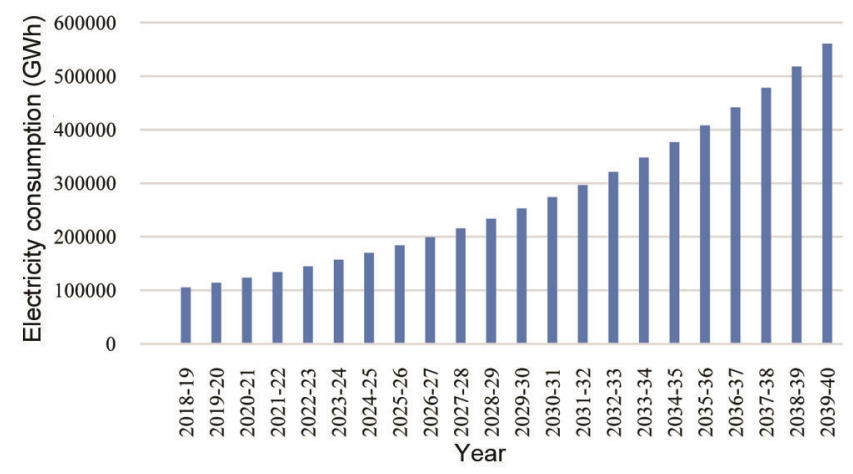

Figure 9. Forecasted electricity consumption (GWh) for commercial sector (2018-40).

CURRENT SCIENCE, VOL. 121, NO. 3, 10 AUGUST 2021 
Table 5. Category-wise forecast of electricity consumption (GWh)

\begin{tabular}{lccccccr}
\hline & \multicolumn{3}{c}{$2019-20$} & & \multicolumn{3}{c}{$2021-22$} \\
\cline { 2 - 3 } Category & $\begin{array}{c}\text { Central Electricity } \\
\text { Authority }\end{array}$ & Predicted & Difference & & $\begin{array}{c}\text { Central Electricity } \\
\text { Authority }\end{array}$ & Predicted & Difference \\
\hline Domestic & 333,356 & 397,211 & 63,855 & & 386,790 & 478,888 & 92,098 \\
Commercial & 112,630 & 114,104 & 1474 & & 128,888 & 133,795 & 4907 \\
Industries & 341,492 & 414,132 & 72,640 & & 386,450 & 462,934 & 76,484 \\
Others & 109,818 & $77,578.1$ & $-32,240$ & & 122,081 & $90,657.2$ & $-31,424$ \\
Total & $1,144,579$ & $1,259,026$ & 114,447 & & $1,300,486$ & $1,444,175$ & 143,689 \\
\hline
\end{tabular}

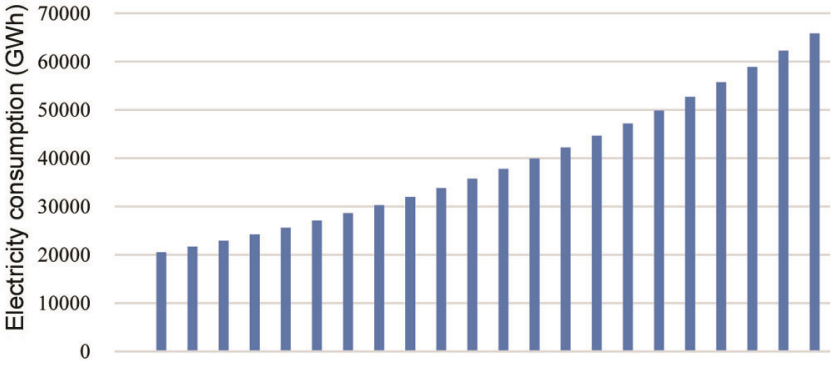

ำิ

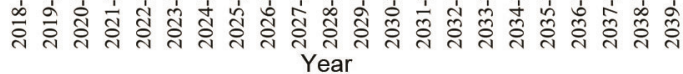

Figure 10. Forecasted electricity consumption $(\mathrm{GWh})$ for traction and railways sector (2018-40).

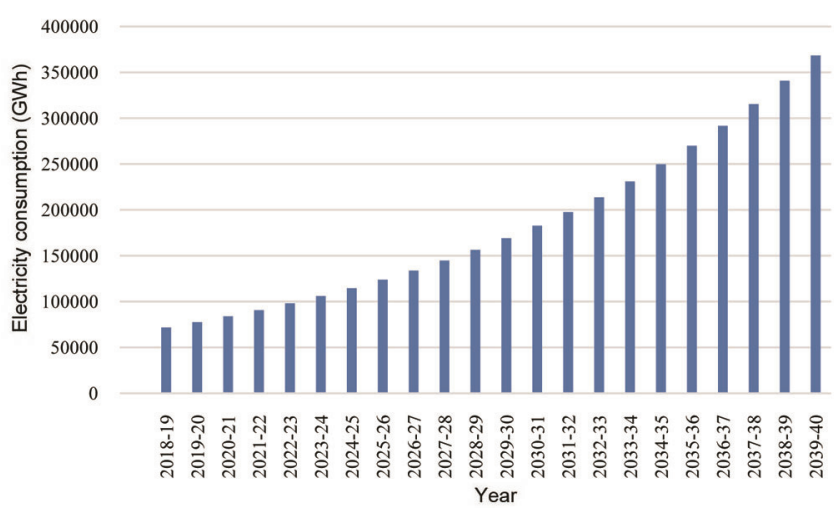

Figure 11. Forecasted electricity consumption (GWh) for other sectors (2018-2040).

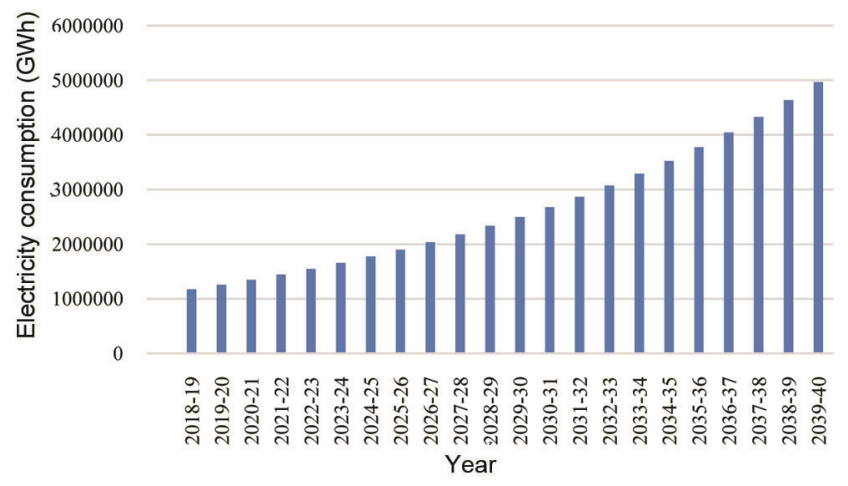

Figure 12. Forecasted total electricity consumption (GWh; 20182040). in 2030-31. Similar trend will follow in the next 10 years, thus increasing the electricity consumption in the domestic sector to $560,656 \mathrm{GWh}$.

\section{Traction and railways sector}

Figure 10 shows the increasing future trend in the traction and railways sector. In 2020-21, electricity consumption will be at $22,923.4 \mathrm{GWh}$ which will increase to $39,931.2 \mathrm{GWh}$ in $2030-31$. Further, the consumption of electricity will increase to $65,802.6 \mathrm{GWh}$ in $2039-40$.

\section{Other sectors}

Figure 11 shows an increase in the consumption of electricity in other sectors. The electricity consumption will increase from 77,578.1 GWh in 2019-20 to $169,065 \mathrm{GWh}$ in 2029-30. In 2039-40, electricity consumption will increase to $368,443 \mathrm{GWh}$.

\section{Total electricity consumed}

As observed from Figure 12, the total electricity consumption shows an increasing trend from 1,259,026 GWh in 2019-20 to 2,500,119 GWh in 2029-30. This will further increase to $4,964,628 \mathrm{GWh}$ in $2039-40$.

\section{Validation of obtained results}

Validation of the present study was done by comparing the available forecasted data published by the CEA in report titled 'Growth of electricity sector in India from 1947-2019' published in May 2019. Since the forecast published by the GoI is for the years 2019-20 and 202122 , comparison could be done only for these two years. Also, the CEA data were available only for five sectors, namely industry, domestic, commercial, others and total electricity consumed, out of seven being forecasted in this study. Table 5 shows forecasted values by both CEA and the present study.

Figure 13 shows the comparative analysis of forecast presented by CEA and this study. It can be seen that the increasing trends of both forecasts match well. However, 


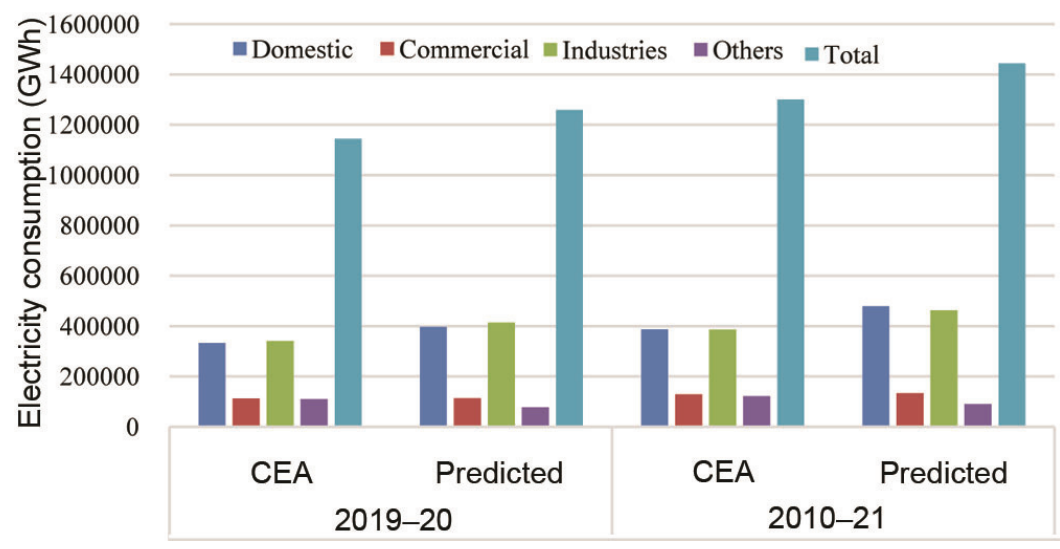

Figure 13. Comparative analysis of forecast with Central Electricity Authority data.

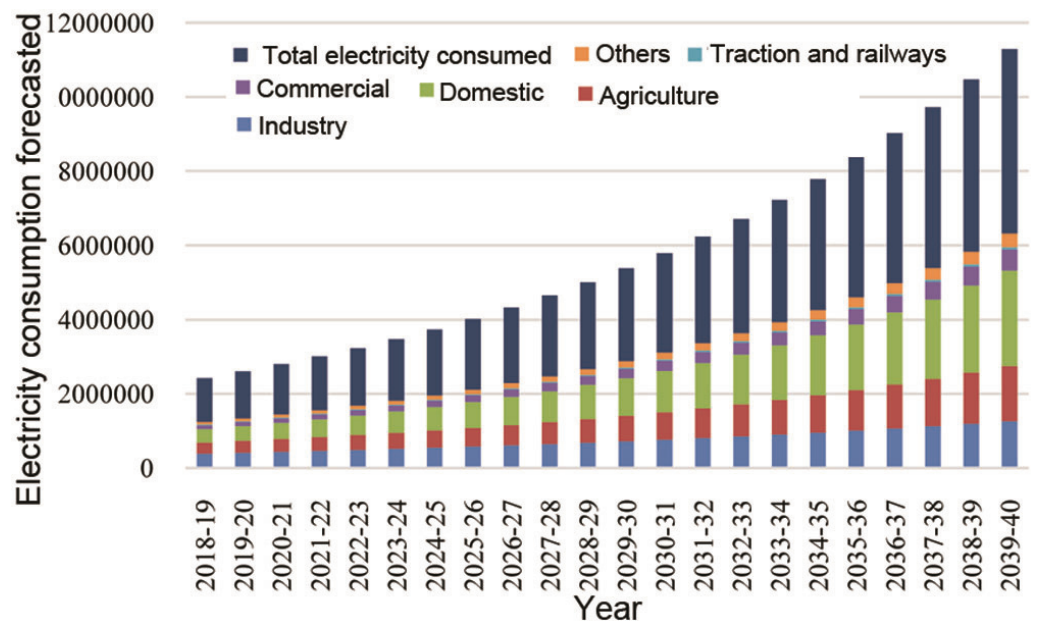

Figure 14. Forecasted sector-wise electricity consumption.

as shown in Table 5, there is a slight difference in the values.

\section{Conclusion}

In the present study, forecasting models are developed for electricity consumption by different sectors in India. This study will be helpful to energy planners to prepare for the demand in electricity in various sectors in the next few years. Also, it will be useful for the development of the required electricity infrastructure. The main conclusions of the study are summarized below.

- The coefficient of determination for all the selected regression models is higher than 0.93 , thus indicating high reliability of the models for the sector-wise electricity consumption forecasting.

- The proposed models have small values of MAPE, which suggests that they can be successfully used as a forecasting tool for electricity consumption.
- The study reveals that among the various regression models, the exponential regression model shows the best forecasting performance.

Future studies should focus on the forecasting of electricity consumption using other methods, including ANN, programming, time-series models, etc. They can also include other important variables such as GDP, population and others affecting electricity consumption.

Figure 14 shows the forecasted sectorwise electricity consumption. In 2018-19, the industrial sector shows an electricity consumption of $391,696 \mathrm{GWh}$, which will increase to $1,261,662 \mathrm{GWh}$ by 2040 . Whereas, the agricultural sector shows the consumption of 293,302 GWh in 2018-19 and 686,429 GWh in 2029-30, which will increase to $1,486,981 \mathrm{GWh}$ in 2039-40. In the domestic sector, 361,755 GWh was consumed in 2018-19, which will increase to $2,577,222 \mathrm{GWh}$ in $2039-40$. The commercial sector will show an increase to $252,929 \mathrm{GWh}$ in 2029-30 and 560,656 GWh in 2039-40. Railways and traction shows an electricity consumption of $20,515 \mathrm{GWh}$ 
in 2018-19 which will rise to $65,802 \mathrm{GWh}$ in $2039-40$. The 'others' sector shows a consumption of $169,065 \mathrm{GWh}$ in 2029-30, which will increase to $368,443 \mathrm{GWh}$ in 2039-40. The total electricity consumption in 2018-19 was $1,175,553 \mathrm{GWh}$, which will show an exponential increase to 4,964,628 GWh in 2039-40.

The results of the present study show that there will be an exponential increase in electricity consumption of all sectors. To cope with this demand, energy manufacturers and developers should increase the infrastructure and production of electricity. While increasing production, focus should be given to the fact that maximum energy should be generated using renewable energy sources such as solar power, wind power, etc. This will help in the conservation of non-renewable energy sources such as coal, natural gas, etc. Thus, the present study will help policymakers in designing and developing future energy policies related to the consumption and production of electricity in India.

1. Morales, A. and Acevedo, A.M., Forecasting future energy demand: electrical energy in Mexico as an example case. Energy Procedia, 2014, 57, 782-790.
2. Bianco, V., Manca, O. and Nardini, S., Linear regression models to forecast electricity consumption in Italy. Energy Sour., Part B, 2013, 8(1), 86-93.

3. Çunkas, M. and Taskiran, U., Turkey's electricity consumption forecasting using genetic programming. Energy Sour., Part B, 2011, 6, 406-416.

4. Ghosh, S. and Das A., Short-run electricity demand forecasts in Maharashtra. Appl. Econ., 2002, 34(8), 1055-1059, doi:10.1080/ 00036840110064656.

5. Guerrero, V. M. and Berumen, E., Forecasting electricity consumption with extra-model information provided by consumers. J. Appl. Stat., 1998, 25(2), 283-299.

6. Panklib, K., Prakasvudhisarn, C. and Khummongkol, D., Electricity consumption forecasting in Thailand using an artificial neural network and multiple linear regression. Energy Sour., Part B, 2015, 10(4), 427-434; doi:10.1080/15567249.2011.559520.

7. Rao, S. R. and Ghosh, S., Forecasting monthly peak demand of electricity in India - a critique. Energy Policy, 2012, 45, 516-520.

8. Sigauke, C. and Chikobvu, D., Peak electricity demand forecasting using time series regression models: an application to South African data. J. Stat. Manage. Syst., 2016, 19(4), 567-586; doi:10.1080/ 09720510.2015 .1086146

Received 28 January 2021; revised accepted 29 March 2021

doi: $10.18520 / \mathrm{cs} / \mathrm{v} 121 / \mathrm{i} 3 / 365-371$ 